\title{
NMR Study on the Relationship between Miscibility and Anti-Aging Performance of Blends Containing Block Copolymers
}

\author{
Hanqiao Feng, ${ }^{\dagger}$ Chaohui Ye, and Zhiliu FenG* \\ Laboratory of Magnetic Resonance and Atomic and Molecular Physics, \\ Wuhan Institute of Physics, Chinese Academy of Sciences, \\ Wuhan 430071, People's Republic of China \\ * Polymer Physics Laboratory, Changchun Institute of Applied Chemistry, \\ Chinese Academy of Sciences, Changchun 130022, \\ People's Republic of China
}

(Received October 19, 1994)

\begin{abstract}
The anti-aging performance of blends of polystyrene (PS), styrene-butadiene triblock copolymers (SBS), and PS/styrene-butadiene (SB)-4A (4-arm star SB block copolymer) has been studied by means of ${ }^{13} \mathrm{C} \mathrm{NMR}$ techniques. It is found that the anti-aging performance of these kinds of blends largely depends on their miscibility with PS of different molecular weight $M_{\mathrm{PS}}$. The larger the quantities of PS solubilized in polybutadiene (PBD) domains, the better the anti-aging performance of the blends. It is also found that the anti-aging performance of these blends has dependence on molecular architectures of the SB block copolymers. For the aged blends, the double bonds of PBD were broken, meanwhile serious cross-linking networks formed in the blends. The proposed anti-aging mechanism is that the PS solubilized in PBD domains can efficiently prevent oxygen molecules from diffusing into PBD domains, therefore, successfully stop the oxidative process of PBD.

KEY WORDS Blends / Miscibility / Anti-Aging Performance / CrossLinking / ${ }^{13} \mathrm{C}$ CPMAS NMR /
\end{abstract}

Recently much attention has been paid to the miscibility and morphology of homopolymer/block copolymer blends ${ }^{1-10}$ since block copolymers often give well defined microstructures which play a key role in determining their macroscopic properties. However, less attention has been paid to the molecular motions and macroscopic properties of this kind of blends. So far as we know, even almost no report on the relationship between their miscibility and anti-aging performance has been made. However, the anti-aging performance of a blend system is a key factor determining its practical application. $\mathrm{We}^{11-13}$ have made studies on the miscibility, morphology, and molecular motions of blends of two styrene-butadiene (SB) block copolymers, triblock (SBS), and four-arm star block (SB-4A), with homopolymer polystyrene (PS) of different molecular weights by means of NMR, SAXS, and dynamical mechanical analysis (DMA) techniques. It was found that the miscibility of PS/SBS and PS/SB-4A blends depends on the molecular weight $\left(M_{\mathrm{PS}}\right)$ of PS, but little on the molecular architectures of SB block copolymers; there exists an optimal range of $M_{\mathrm{PS}}$ within which the blends will give rise to a well improved macroscopic properties: enhancing their plateau modulus and enlarging their temperature range between the low and high glass transitions; there are detectable quantities of PS chains solubilized in polybutadiene (PBD) block domains, for the blends in which PS is miscible with PS block domain,

\footnotetext{
† To whom correspondence should be addressed.
} 
the smaller the $M_{\mathrm{PS}}$, the more the quantities of PS solubilized in PBD domains, but the situation is just opposite for the blends in which PS is immiscible or partially miscible with PS block domain, i.e., the larger the $M_{\mathrm{PS}}$, the more the quantities of PS solubilized in PBD block domains. Besides, the results from variable temperature NMR experiments of these blends indicate both the low and high glass transition temperatures of PS block and PBD block in the blends largely depend on the $M_{\mathrm{PS}}$ of PS added.

In this work, the specimens, which had been used for NMR measurements at room temperature and were deposited in doors under ambient atmosphere for near a year, are used to study the relationship between their miscibility and anti-aging performance under ambient atmosphere.

\section{EXPERIMENTAL}

The characteristic data of the polymers are listed in Tables I and II, and some important properties of these blends before and after aging are listed in Tables III and IV.

${ }^{13} \mathrm{C}$ CPMAS NMR experiments were

Table I. Molecular characteristics of homopolystyrenes

\begin{tabular}{lccc}
\hline Sample & $M_{n} \times 10^{-4}$ & $M_{w} / M_{n}$ & $T_{\mathrm{g}} / \mathrm{K}$ \\
\hline PS03 & 0.34 & 1.05 & 339.3 \\
PS1 & 0.97 & 1.03 & 367.0 \\
PS12 & 12.5 & 1.06 & 371.8 \\
PS100 & 97.4 & 1.08 & 374.5 \\
\hline
\end{tabular}

Table II. Molecular characteristics of block copolymers

\begin{tabular}{|c|c|c|c|}
\hline \multirow{2}{*}{ Sample } & \multirow{2}{*}{$M_{n} \times 10^{-4 a}$} & $\mathbf{S} / \mathbf{B}^{\mathbf{b}}$ & PS \\
\hline & & $w t \%: w t \%$ & $M_{n} \times 10^{-4}$ \\
\hline SBS. & 6.70 & $44 / 56$ & 1.47 \\
\hline $\mathrm{SB}-4 \mathrm{~A}^{\mathrm{c}}$ & 15.43 & $45 / 55$ & 1.73 \\
\hline
\end{tabular}

${ }^{a}$ Determined by membrane osmometry in toluene at $37^{\circ} \mathrm{C}$. ${ }^{b}$ Determined by ${ }^{13} \mathrm{C}$ NMR. ${ }^{\mathrm{c}}$ PS blocks locate at the outer end of the copolymer chains. performed on a Bruker MSL-400 MHz NMR spectrometer at $298.0 \mathrm{~K}$. TOSS method was used for suppressing the spinning side band. The ${ }^{13} \mathrm{C}$ resonance frequency was $100.63 \mathrm{MHz}$, and ${ }^{1} \mathrm{H}$ resonance frequency was $400.13 \mathrm{MHz}$. A $4.6 \mu \mathrm{s} 90^{\circ}$ pulse for ${ }^{13} \mathrm{C}$ and a $6.1 \mu \mathrm{s} 90^{\circ}$ pulse for ${ }^{1} \mathrm{H}$ were used. The contact time was $1.5 \mathrm{~ms}$. The delay time was $2 \mathrm{~s}$. The ${ }^{13} \mathrm{C}$ spectra were referred to the chemical shift of methyl carbons of hexamethylbenzene which was $16.9 \mathrm{ppm}$.

Table III. $T_{\mathrm{g}}{ }^{\mathrm{a}} \mathrm{s}^{\mathrm{a}}$ of SBS, SB-4A, and their blends with PS ${ }^{\mathrm{b}}$

\begin{tabular}{lcc}
\hline Sample & $T_{\mathrm{g} 1} /{ }^{\circ} \mathrm{C}$ & $T_{\mathbf{g} 2} /{ }^{\circ} \mathrm{C}$ \\
\hline SB-4A & -86.9 & +99.1 \\
PS03/SB-4A & -90.2 & +93.2 \\
PS1/SB-4A & -88.6 & +106.1 \\
PS12/SB-4A & -86.0 & +97.1 \\
PS100/SB-4A & -84.2 & +97.1 \\
SBS & -87.0 & +98.9 \\
BS03/SBS & -87.5 & +93.2 \\
PS1/SBS & -85.9 & +105.1 \\
PS12/SBS & - & - \\
PS100/SBS & -86.0 & +97.1
\end{tabular}

${ }^{a}$ Determined by DMA, $T_{\mathrm{g} 1}-T_{\mathrm{g}}$ of PBD; $T_{\mathrm{g} 2}-T_{\mathrm{g}}$ of PS.

${ }^{\mathrm{b}}$ All the blends contain $20 \%$ PS by weight.

Table IV. Physical properties of SBS, SB-4A and their blends ${ }^{\mathrm{a}}$ with PS before and after aging

\begin{tabular}{|c|c|c|}
\hline Sample & Before aging & After one-year aging \\
\hline SB-4A & $\begin{array}{c}\text { Transparent } \\
\text { colorless }\end{array}$ & Light yellow \\
\hline PS03/SB-4A & $\begin{array}{c}\text { Transparent, } \\
\text { colorless }\end{array}$ & $\begin{array}{c}\text { Transparent } \\
\text { colorless }\end{array}$ \\
\hline PS1/SB-4A & $\begin{array}{c}\text { Transparent, } \\
\text { colorless }\end{array}$ & $\begin{array}{c}\text { Transparent, } \\
\text { colorless }\end{array}$ \\
\hline PS12/SB-4A & Opaque, white & Yellow \\
\hline PS100/SB-4A & Opaque, white & Yellow \\
\hline SBS & $\begin{array}{l}\text { Transparent, } \\
\text { colorless }\end{array}$ & Heavy yellow \\
\hline PS03/SBS & $\begin{array}{c}\text { Transparent, } \\
\text { colorless }\end{array}$ & $\begin{array}{c}\text { Transparent, } \\
\text { colorless }\end{array}$ \\
\hline PS1/SBS & $\begin{array}{l}\text { Transparent, } \\
\text { colorless }\end{array}$ & Light yellow \\
\hline PS12/SBS & $\begin{array}{l}\text { Opaque, light } \\
\text { yellow }\end{array}$ & Heavy yellow \\
\hline PS100/SBS & Opaque, white & Yellow \\
\hline
\end{tabular}

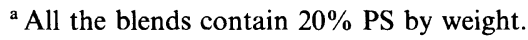




\section{RESULTS AND DISCUSSION}

Shown in Figure 1 are the ${ }^{13} \mathrm{C}$ CPMAS NMR spectra of blends of SBS with PS of different molecular weight before and after aging. It is known that the peaks around 28.0 and $33.1 \mathrm{ppm}$ are assigned to the saturated methylene carbons of cis-1,4-, trans-1,4-, and 1,2 butadiene units in SB copolymers, ${ }^{14,15}$ and the signal around $130.0 \mathrm{ppm}$ is assigned to the unsaturated carbons $\mathrm{C}=\mathrm{C}$ of butadiene unit in SB copolymers. As compared to the ${ }^{13} \mathrm{C}$ spectra (Figures 1(a), (b), and (c)) of PS100/SBS, PS1/SBS, and PS03/SBS blends without aging, the ${ }^{13} \mathrm{C}$ spectra (Figures $1\left(a^{\prime}\right)$, $\left(b^{\prime}\right)$, and $\left(c^{\prime}\right)$ ) of the corresponding blends undergone one-year natural aging have several features worthy to be mentioned: (1) In part (a), (b), and (c) of Figure 1, the peaks at 33.1 and $28.0 \mathrm{ppm}$ are well defined, and the peak at $130.1 \mathrm{ppm}$ has the highest intensity among the peaks. In part $\left(a^{\prime}\right)$ and $\left(b^{\prime}\right)$ of Figure 1 , however,

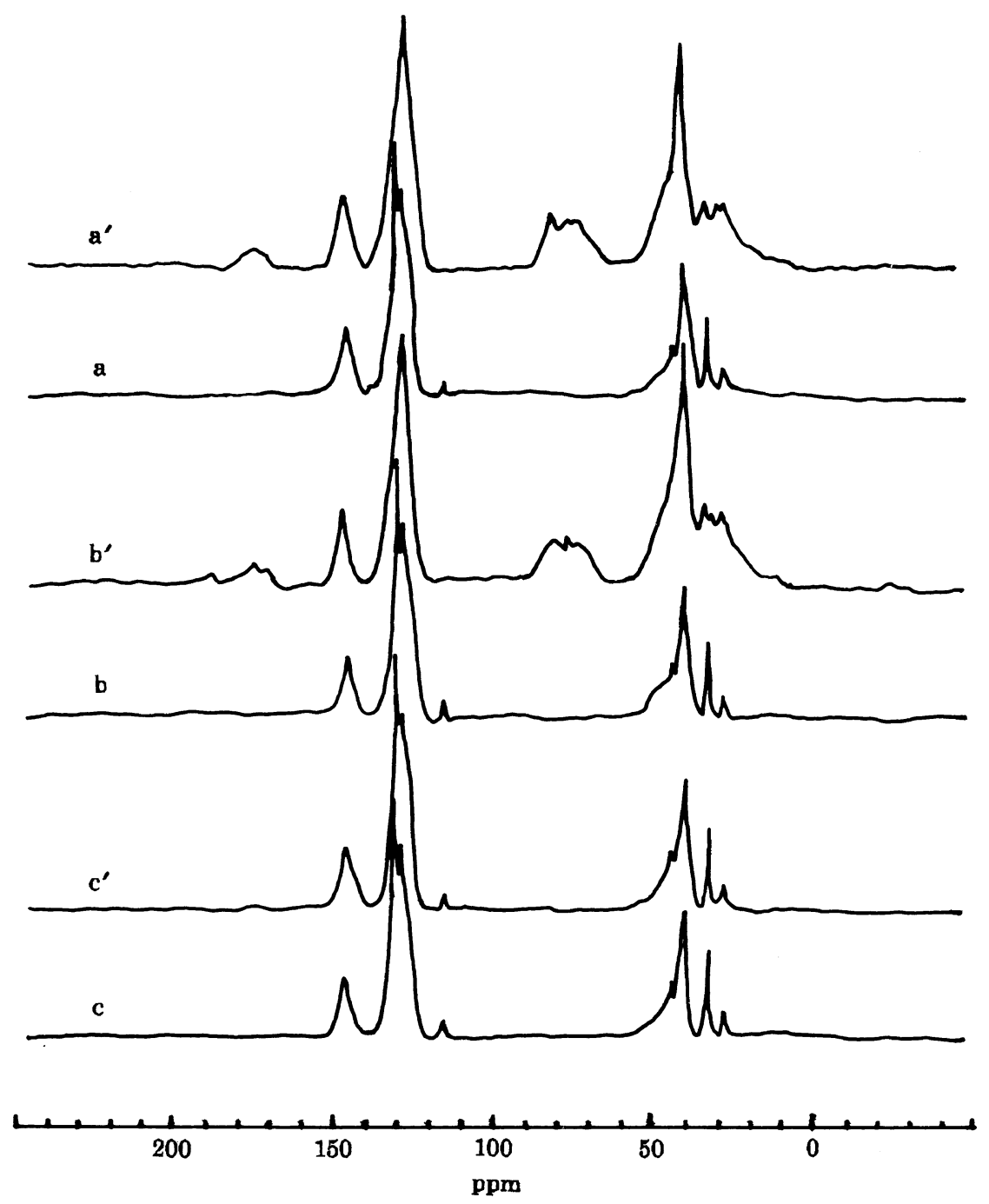

Figure 1. ${ }^{13} \mathrm{C}$ CPMAS NMR spectra of non-aging blends: (a) PS100/SBS, (b) PS1/SBS, (c) PS03/SBS, and one-year aging blends: $\left(a^{\prime}\right)$ PS100/SBS, $\left(b^{\prime}\right)$ PSI/SBS, and $\left(c^{\prime}\right)$ PS03/SBS. 
some marked differences occur, the peaks at 33.1 and $28.0 \mathrm{ppm}$ are seriously broadened, and the peak at $130.1 \mathrm{ppm}$ disappears. (2) In part (a), (b), and (c) of Figure 1, no signals are observed in the range of $170-180$ and $70-90 \mathrm{ppm}$, but in part $\left(\mathrm{a}^{\prime}\right)$ and $\left(\mathrm{b}^{\prime}\right)$ of Figure 1 two new seriously broadened peaks appear in the range of $170-180$ and $70-90 \mathrm{ppm}$, respectively. Undoubtedly, it is the aging of the blends that gives rise to the significant changes. It should be noted that when the molecular weight of PS is in the range of $10000-1000000$ the spectra of aged PS/SBS blends will all include the two new peaks mentioned above, although there are slight differences in shape and intensity depending on the difference of molecular weight of PS.

Figure 2 shows the ${ }^{13} \mathrm{C}$ CPMAS NMR spectra of blends of SB-4A with PS of different molecular weights before and after aging. The situation in Figure 2 is different from that in Figure 1 because the marked changes: the

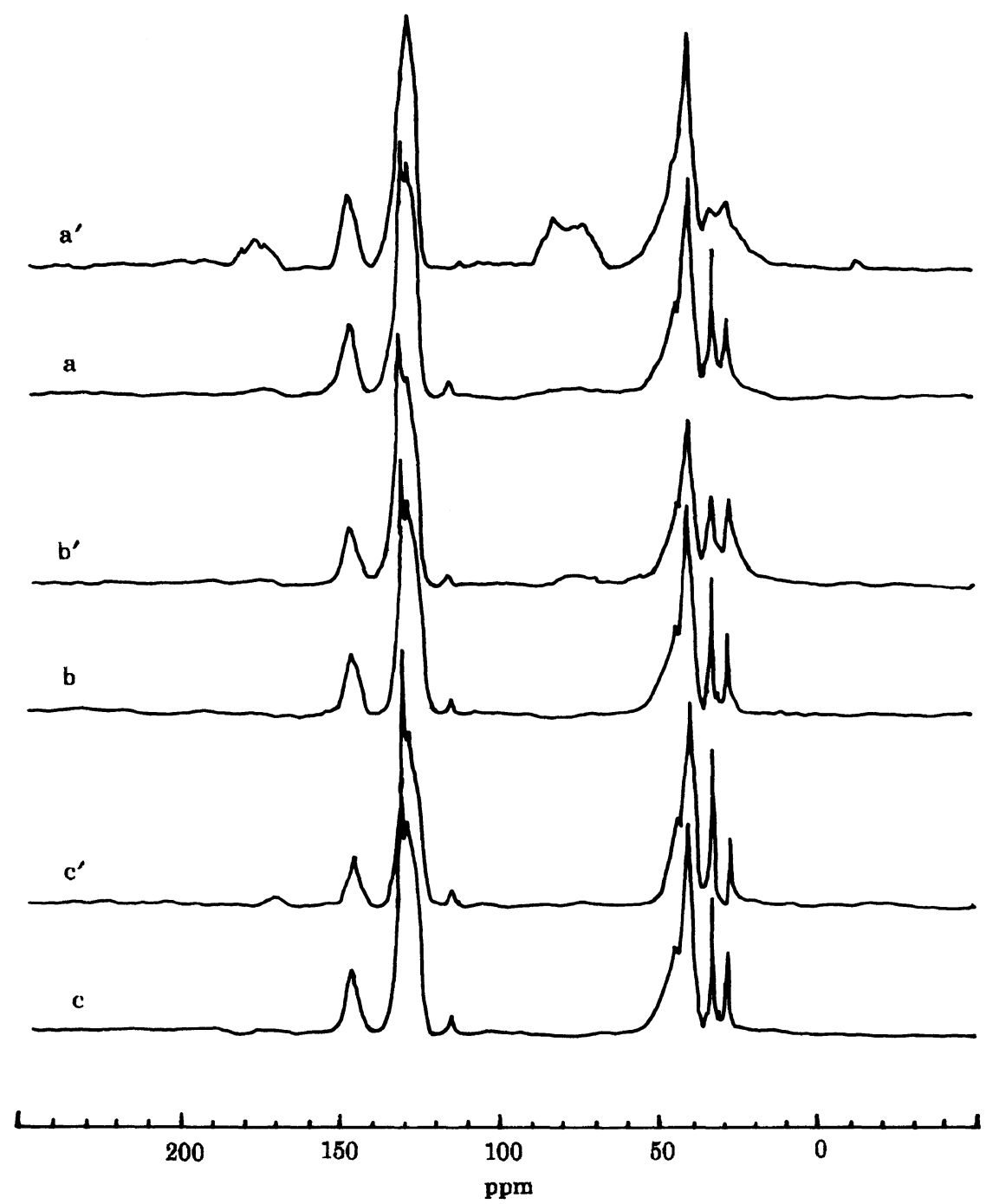

Figure 2. ${ }^{13} \mathrm{C}$ CPMAS NMR spectra of non-aging blends: (a) PS100/SB-4A, (b) PS1/SB-4A, (c) PS03/SB-4A, and one-year aging blends: (a') PS100/SB-4A, (b') PS1/SB-4A, and (c') PS03/SB-4A. 
disappearance of peak at $130.1 \mathrm{ppm}$, the broadening of peaks at 33.1 and $28.0 \mathrm{ppm}$, and the appearance of two new broadened peaks in the range of $170-180$ and $70-90 \mathrm{ppm}$, etc., occur in Figure $1\left(b^{\prime}\right)$ but not in Figure $2\left(b^{\prime}\right)$ as the $M_{\mathrm{PS}}$ in these blends is the same. When the $M_{\mathrm{PS}}$ is smaller than 20000 , no appreciable changes can be observed in the ${ }^{13} \mathrm{C}$ NMR spectra of the aged PS/SB-4A blends.

As well known, the resonant peaks of carbonyl carbons $\mathrm{C}=\mathrm{O}$ appear in the range of $170-180 \mathrm{ppm}$, and the carbons directly attached to hydroxyl group - $\mathrm{OH}$ and ether group - $\mathrm{O}-$ contribute the peaks around $70-90$ ppm. $^{16}$ Therefore, it is apparent that during the naturally aging process of PS/SBS and PS/SB-4A belnds some new substances:
$\mathrm{C}=\mathrm{O}, \stackrel{\mathrm{O}}{\stackrel{\mathrm{C}}{\mathrm{C}}-\mathrm{O}-}-\stackrel{\mathrm{O}}{\mathrm{C}}-\mathrm{C}-\mathrm{OH},-\mathrm{O}-$, and $-\mathrm{OH}$ have formed.

Figure 3 shows another picture. Figures 3(a), (b), and (d) are, respectively, the ${ }^{13} \mathrm{C}$ CPMAS NMR spectra of PS100/SBS, PS12/SB-4A, and PS12/SBS blends not aged for one-year naturally but thermally processed at $100^{\circ} \mathrm{C}$ under vacuum for five days. Apparently, aging occured for PS12/SBS (Figure 3(d)) as the peak at $130.1 \mathrm{ppm}$ disappeared and the peaks at 33.1 and $28.0 \mathrm{ppm}$ are broadened, but this aging process did not occurs for PS/SB-4A and PS100/SBS blends. Besides, marked differences exist between Figures 3(c) and (d) which are the spectra of the thermally aged PS12/SBS blends before and after standing for one-year natural aging, respectively. In Figure 3(d) the

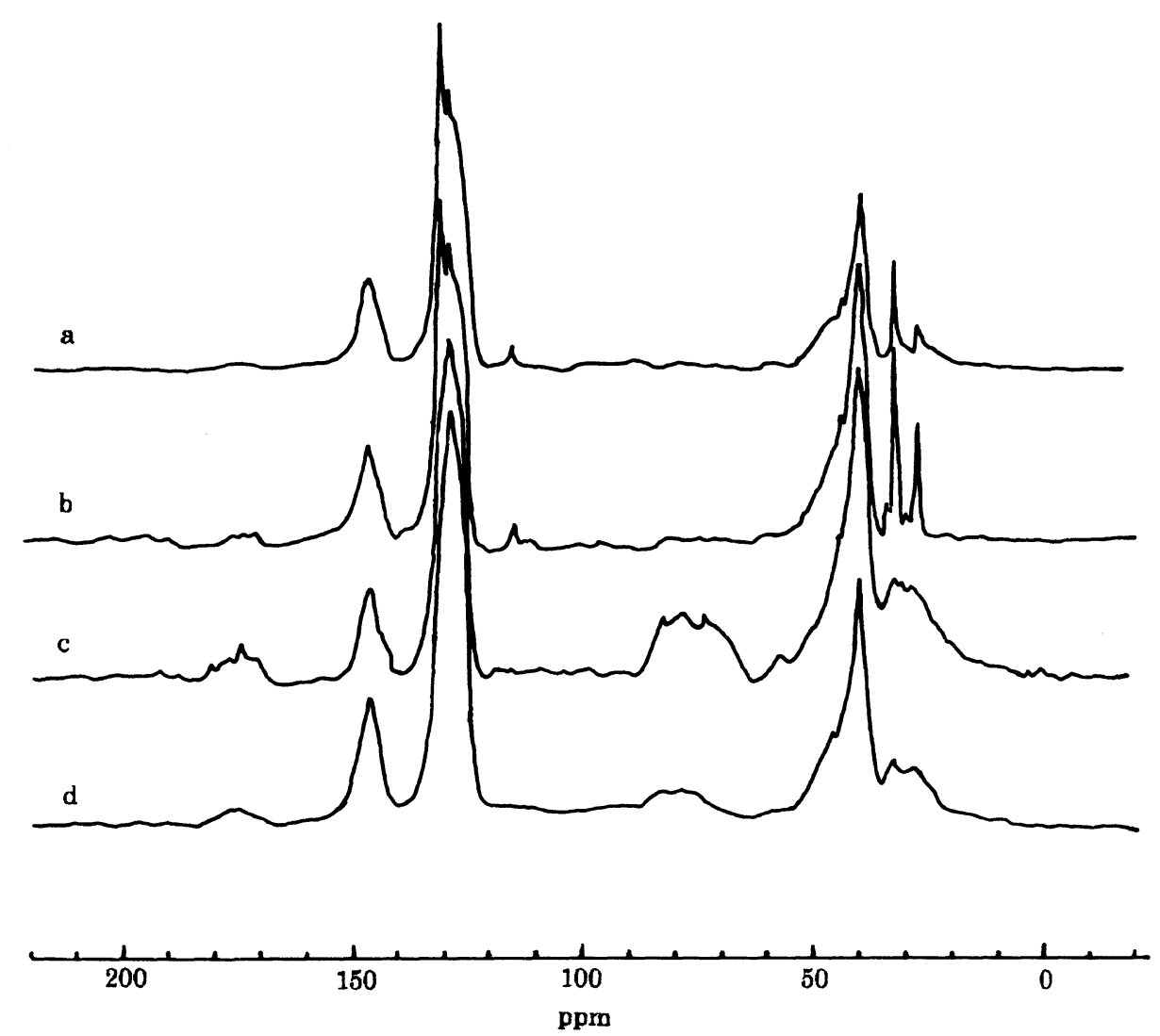

Figure 3. ${ }^{13} \mathrm{C}$ CPMAS NMR spectra of blends: (a) non-aging PS100/SBS, (b) non-aging PS12/SB-4A, (c) one-year aging PS12/SBS, and (d) thermal aging PS12/SBS. 
intensities of the two new peaks in the range of $70-90$ and $170-180 \mathrm{ppm}$ are much smaller than those of the corresponding peaks in Figure 3(c), which means that there are very small quantities of oxidative products formed during the thermal aging process of PS12/SBS blends.

Therefore, according to the results of Figures 1,2 , and 3 , the following conclusions can be drawn: (1) The anti-aging performance of blends of SB blcok copolymers with PS largely depends on their miscibility, in fact, on the quantities of PS solubilized in PBD block domains. For the blends in which PS is miscible with PS block, the smaller the $M_{\mathrm{PS}}$, the more the quantities of PS chains solubilized in PBD block domains, the better the anti-aging performance of the blends; For the blends in which PS is partially miscible with PS block, the larger the $M_{\mathrm{PS}}$, the more the quantities of PS chains mechanically mixed into PBD block domains by random entanglements, the better the anti-aging performance of the blends. As a result, the anti-aging performance of PS/SBS blends obeys the following orders: PS03/SBS $>$ PS1/SBS $>$ PS100/SBS $>$ PS12/SBS. Similar sit- uation also occurs for PS/SB-4A blends. (2) The anti-aging performance of PS/SB block copolymer blends has dependence on the molecular architectures of the SB block copolymers. When the $M_{\mathrm{PS}}$ is the same, PS/SB-4A blends have a better anti-aging performance than PS/SBS blends. (3) The thermal aging mechanism of these blends are different from the natural aging one. A typical example is the aging of PS12/SBS blends. When PS12/SBS blends underwent a thermal process at $100^{\circ} \mathrm{C}$ under vacuum for five days, the double bonds $\mathrm{C}=\mathrm{C}$ of PBD in blends were broken as its resonant peak at $130.1 \mathrm{ppm}$ disappears (see Figure 3(d)), at the same time, the peaks at 33.1 and $28.0 \mathrm{ppm}$ are seriously broadened, but only two very small dunes in the range of $70-90 \mathrm{ppm}$ and $170-180 \mathrm{ppm}$ are observed in Figure 3(d). However, for all the naturally aged blends, in their ${ }^{13} \mathrm{C}$ NMR spectra there are two big and broadened peaks in the corresponding ranges which appear just due to the formation of new oxidative products in the aged blends. Hence, during the thermal aging process of these blends the double bonds in

Table V. The $T_{1 \rho}(H)$ values $(\mathrm{ms})^{\mathrm{a}}$ of SBS, SB-4A, and their blends ${ }^{\mathrm{b}}$ with PS before and after aging

\begin{tabular}{|c|c|c|c|c|c|c|c|c|}
\hline \multirow{3}{*}{ Sample } & \multicolumn{4}{|c|}{ Before aging } & \multicolumn{4}{|c|}{ After one-year aging } \\
\hline & \multicolumn{2}{|c|}{ PS $(40.0 \mathrm{ppm})$} & \multicolumn{2}{|c|}{ PBD (33.1 ppm) } & \multicolumn{2}{|c|}{ PS $(40.0 \mathrm{ppm})$} & \multicolumn{2}{|c|}{$\operatorname{PBD}(33.1 \mathrm{ppm})$} \\
\hline & $T_{1 \rho}(H)$ & $\%$ & $T_{1 \rho}(H)$ & $\%$ & $T_{1 \rho}(H)$ & $\%$ & $T_{1 \rho}(H)$ & $\%$ \\
\hline \multirow[t]{2}{*}{ SBS } & 26.4 & 7.1 & 15.7 & 77.5 & 5.7 & 100 & 5.7 & 100 \\
\hline & 4.1 & 92.9 & 1.9 & 22.5 & & & & \\
\hline \multirow[t]{2}{*}{ PS1/SBS } & 30.9 & 10.5 & 15.7 & 66.2 & 5.8 & 100 & 5.7 & 100 \\
\hline & 3.9 & 89.5 & 1.5 & 33.8 & & & & \\
\hline \multirow[t]{2}{*}{ PS12/SBS } & 4.5 & 100 & 11.0 & 18.6 & 5.5 & 100 & 5.0 & 100 \\
\hline & & & 5.3 & 81.6 & & & & \\
\hline PS100/SBS & 9.3 & 30.3 & 13.0 & 43.2 & 5.3 & 100 & 5.7 & 100 \\
\hline \multirow[t]{2}{*}{ SB-4A } & 4.8 & 100 & 15.5 & 82.8 & 4.9 & 100 & 12.5 & 21.1 \\
\hline & & & 1.4 & 17.2 & & & 2.7 & 78.9 \\
\hline \multirow[t]{2}{*}{ PS03/SB-4A } & 16.9 & 15.1 & 16.5 & 72.0 & 12.9 & 36.0 & 18.9 & 40.9 \\
\hline & 3.4 & 84.9 & 2.4 & 28.0 & 5.9 & 64.0 & 6.0 & 59.1 \\
\hline \multirow[t]{2}{*}{ PS1/SB-4A } & 21.2 & 13.0 & 19.7 & 67.0 & 11.1 & 32.1 & 8.0 & 100 \\
\hline & 3.8 & 87.0 & 3.7 & 33.0 & 3.1 & 67.9 & & \\
\hline \multirow[t]{2}{*}{ PS100/SB-4A } & 10.6 & 12.1 & 15.4 & 64.9 & 5.9 & 100 & 14.8 & 35.7 \\
\hline & 4.9 & 87.9 & 2.6 & 35.1 & & & 3.5 & 64.3 \\
\hline
\end{tabular}

${ }^{\mathrm{a}}$ Estimated error $< \pm 5 \%$. ${ }^{\mathrm{b}}$ All the blends contain $20 \%$ PS by weight. 
PBD are broken by company with the formation of slight cross-linking and of small quantities of oxidative products, but during the natural aging process of these blends, the breakage of the double bonds in PBD is accompanied by the formation of serious cross-linking and large quantities of new oxidative products.

The above conclusions are supported further by the ${ }^{1} \mathrm{H}$ spin-lattice relaxation times in the rotating frame and physical properties of the blends (see Tables IV and V). For all the non-aging blends, there are two $T_{1 \rho}(H)$ values for the peak at $33.1 \mathrm{ppm}$ of PBD. The longer $T_{1 \rho}(H)$ value is assigned to the PBD block in bulk, and the shorter one is assigned to the PBD chains locate in the interface between the bulk PBD domain and the bulk PS domain. Obviously, the addition of PS with different $M_{\mathrm{PS}}$ into SBS or SB-4A has little effect on the $T_{1 \rho}(H)$ values of PBD but has marked effect on the percentage of the longer $T_{1 \rho}(H)$ component of PBD. In fact, the percentage of the longer $T_{1 \rho}(H)$ component of PBD decreases with the increase in molecular weight of PS added. The situation is quite different for the blends undergone one-year natural aging: For SBS and its blends with PS of different $M_{\mathrm{PS}}$, when the $M_{\mathrm{PS}}$ of PS is greater than 10000 , both PS and PBD in the blends have a single and equal $T_{1 \rho}(H)$ value which suggests the formation of a big cross-linking network and the complete loss of elasticity of PBD in these blends. This conclusion is supported by their solubility. The non-aging blends are easily soluble in good solvents such as chloroform, toluene and tetrahydrofuran, etc., but the aged blends can almost neither solublize nor swell in these solvents. Besides, for the thermal aged PS12/SBS blends, there exist some quantities of longer $T_{1 \rho}(H)$ component in PBD. This shows the existence of elasticity in the thermal aged PS12/SBS blends, and again indicates that the thermal aging mechanism is different from the natural aging one for these blends. For SB-4A and its blends with PS of different $M_{\mathrm{PS}}$, there are two features worthy to be mentioned: (1) All the PS/SB-4A blends undergone one-year natural aging contains longer $T_{1 \rho}(H)$ component in different degrees, indicating the existence of elasticity in these blends. (2) The percentage of the longer $T_{1 \rho}(H)$ component in the PS/SB-4A blends without standing for aging is larger than that in the corresponding blends undergone one-year aging. This suggests that one-year natural aging process results in obvious changes of morphological structure of PS/SB-4A even though no marked changes can be observed in their ${ }^{13} \mathrm{C}$ spectra (Figures 2(b) and (c)). Therefore, there also exists crosslinking in some degree in PS03/SB-4A and PS1/SB-4A blends. In this case the crosslinking mechanism is a simple, nonradical cross-linking through vinyl groups as suggested by Grassie ${ }^{17}$ :

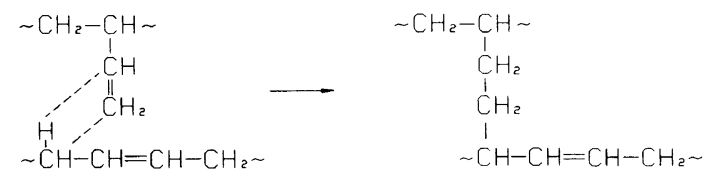

Obvioulsy, the conclusion that PS/SB-4A blends have better anti-aging performance than PS/SBS blends is further supported by the $T_{1 \rho}(H)$ results of these blends. Finally, it should be noted that no detectable aging can be observed for PS in these blends and the homopolymer PS depositing under same conditions as PS/SBS and PS/SB-4A blends.

Usually, the rate of oxidative reaction occurred in a solid polymer is directly proportional to the concentration of oxygen in the polymer. Therefore, oxygen diffusion into a polymer system is rate determining for the oxidative process of the polymer system. ${ }^{18} \mathrm{As}$ expected, PS which normally resists oxidation $^{19}$ does not oxidise (age) and PBD in the blends does under the studied conditions since the diffusion coefficient $D\left(=0.11 \mathrm{~cm}^{2} \mathrm{~s}^{-1}\right)$ of oxygen in the former is much smaller than that $\left(D=1.5 \mathrm{~cm}^{2} \mathrm{~s}^{-1}\right)$ in the latter. ${ }^{20}$ According to the discussions above, it is certain that the main 
aging mechanism of PS/SBS and PS/SB-4A blends is oxidative aging of PBD accompanied by the formation of big cross-linking networks. Without doubt, it is the PS solubilized into PBD domains that give rise to the improved anti-oxidation aging performance of PS/SBS and PS/SB-4A blends. Hence, the resonable anti-oxidation aging mechanism of PS is that the PS solubilized into PBD domains can efficiently provent oxygen from diffusing into PBD domains, depriving oxygen of chance to attack the double bonds of PBD. Naturally, the more the quantities of PS solubilized into PBD domains in the blends the smaller the quantities of oxygen diffused into PBD domains, and the better the anti-oxidation aging performance of PS/SBS and PS/SB-4A blends. Meanwhile, the reason of PS/SB-4A blends having better anti-aging performance than PS/SBS blends is that SB-4A has a better molecular architecture than SBS to form a structure of PS blocks enclosing PBD blocks, making the double bonds in PBD free from attacking by oxygen.

\section{CONCLUSION}

The study on the anti-aging performance of blends of SB blcok copolymers with PS of different molecular weight allows the following conclusions to be drawn:

(1) The anti-aging performance of PS/SBS and PS/SB-4A blends obviously depends on their miscibility, especially on the quantities of PS solubilized into PBD domains. For the blends in which PS is miscible with PS block domains, the smaller the $M_{\mathrm{PS}}$, the more the quantities of PS solubilized in PBD domains, the better the anti-aging performance of the blends. For the blends in which PS is partially miscible with PS block domains, the larger the $M_{\mathrm{PS}}$, the more the quantities of PS chains mechanically mixed into PBD domains by random entanglements, the better the antiaging performance of the blends.

(2) The anti-aging performance of blends of SB block copolymer with PS of different $M_{\mathrm{PS}}$ is related to the molecular architecture of SB block copolymers. When the $M_{\mathrm{PS}}$ of PS added is the same, PS/SB-4A blends have much better anti-aging performance than PS/SBS blends.

(3) The thermal aging mechanism of these blends is quite different from the natural aging one. During the thermal aging process, the double bonds of PBD in blends were broken, meanwhile only a small quantity of oxidation products formed. In the naturally aged blends, a great quantity of oxidative products were found. The breakage of double bonds werẽ accompanied by the formation of big crosslinking networks.

(4) The main aging mechanism of these blends is oxidative break of double bonds of PBD in blends. The proposed anti-aging mechanism of PS is that the PS chains solubilized in PBD domains can efficiently prevent oxygen from diffusing into PBD domains, depriving oxygen of chance to attack double bonds of PBD.

Acknowledgement. The authors are grateful to the financial support granted by the National Basic Research Project-Macromolecular Condensed State, and the Laboratory of Magnetic Resonance and Atomic and Molecular Physics, Wuhan Institute of Physics, Chinese Academy of Sciences.

\section{REFERENCES}

1. T. Hashimoto, S. Koizumi, H. Hasegawa, T. Izumitani, and S. T. Hyde, Macromolecules, 25, 1433 (1992).

2. E. L. Thomas, D. B. Alward, D. L. Kinning, D. C. Martin, D. L. Handlin, Jr. and L. J. Fetters, Macromolecules, 19, 2197 (1986).

3. T. Hashimoto, H. Tanaka, and H. Hasegawa, Macromolecules, 23, 4378 (1990).

4. M. Jiang, X. Cao, and T. Yu, Polymer, 27, 1923 (1986).

5. K. I. Winey, E. L. Thomas, and L. J. Fetters, J. Chem. Phys., 95, 9367 (1991).

6. N. M. Patel, D. W. Dwight, J. L. Hedrick, D. C. Webster, and J. E. McGrath, Macromolecules, 21, 2689 (1988). 
7. H. Tanaka and T. Hashimoto, Macromolecules, 24, 5398 (1991).

8. T. Hashimoto, K. Kimishima, and H. Hasegawa, Macromolecules, 24, 5704 (1991).

9. K. M. Hong and J. Noolandi, Macromolecules, 16, 1083 (1983).

10. M. Banaszak and M. D. Whitmore, Macromolecules, 25, 2757 (1992).

11. H. Feng, Z. Feng, and L. Shen, Macromolecules, in press.

12. H. Feng, Z. Feng, and L. Shen, Macromolecules, in press.

13. H. Feng, Z. Feng, and L. Shen, Macromolecules, in press.

14. A. L. Segre, M. Delfin, F. Conti, and A. Boicelli, Polymer, 16, 338 (1975).
15. H. Sato, T. Ishikawa, K. Takebayashi, and Y. Tanaka, Macromolecules, 22, 1748 (1989).

16. Q. T. Pham, R. Petiaud, M.-F. Llauro, and H. Waton, "Proton and Carbon NMR Spectra of Polymers, Vol. 3, Hermes Publishing Ltd., John Wiley \& Sons, Chichester, 1984.

17. N. Grassie and A. Heaney, J. Polym. Sci., Polym. Lett. Ed., 12, 89 (1974).

18. B. Ranby and F. Rabek, "Photodegration Photooxidation and Photostabilization of Polymers," John Wiley \& Sons, London, 1975.

19. V. R. Gowariker, N. V. Viswanathan, and J. Sreedhar, "Polymer Science," Wiley Eastern Limited, New Delhi, 1986.

20. J. Crank and G. S. Park, "Diffusion in Polymers," Academic Press, New York, N.Y., 1968. 